reproduction as yet another happy hunting-ground for the experimental biologist.

\section{Conclusion}

In this lecture I have tried to look back on 60 years of the physiology of reproduction, especially on the decisive Cambridge contribution, and I have tried to visualize some future trends of work. In doing so I have aimed to give an impression of Marshall's work and influence. Marshall was indeed a great man, and I am proud to hold the Chair which he founded and proud to inaugurate it in the presence of so many of his old friends and colleagues and in this room where so many distinguished scientists, including Marshall, have given of their knowledge.

I will conclude by quoting some words which I wrote in 1949 at the time of Marshall's death. "Scientists are of many kinds, but inspiration flows most fruitfully from those who are able, by some gift withheld from lesser men, to divine the richness of uncharted country and sense the vital landmarks. Thus do they avoid the barren places and the morasses of unimportant detail which engulf so many. To these, discovery is an art rather than a science; a matter of instinct rather than of intellectual machinery. Such was Marshall."

\title{
"ANOVLAR" AS AN ORAL CONTRACEPTIVE
}

BY

ELEANOR MEARS, M.B., Ch.B. Medical Secretary, Council for the Investigation of Fertility Control; Medical Secretary, Family Planning Association

The two most promising and most extensively tested progestational compounds to be used as oral contraceptives are norethynodrel and norethisterone. Norethynodrel was the first to be used in large-scale trials in this country under the auspices of the Council for the Investigation of Fertility Control in Birmingham, Slough, and London, and some of the results have already been published (Eckstein et al ; 1961 ; Mears, 1961). The 5-mg. tablet of norethynodrel containing $0.075 \mathrm{mg}$. of ethinyloestradiol-3-methyl ether (" conovid") was also the first oral contraceptive to be approved by C.I.F.C. for use in Family Planning Association clinics.

Norethisterone (17 $\alpha$-ethinyl-19-nortesterone ; " primolut N," " norlutin") was given as an oral contraceptive by Tyler et al. (1961) to 570 patients for 7,194 cycles over a period of four years. Norethisterone acetate was later used, and 536 women had received this preparation with varying amounts of oestrogen for 2,292 cycles (Peeters et al., 1960, 1961; Margulis et al., 1961 ; Matsumoto et al., 1961 ; Grant, 1961 ; Swyer, 1962) when this trial began.

Two years ago small carefully controlled preliminary trials of norethisterone, norethisterone acetate, with and without oestrogen, were begun as outlined in previous papers (Jackson, 1961 ; Mears, 1961) to assess the ability to postpone menstruation, to inhibit ovulation, and to produce secretory changes in the endometrium. The first large-scale trial began in London in May, 1961, using the dose which seemed to be most satisfactory $-4 \mathrm{mg}$. of norethisterone acetate plus $0.05 \mathrm{mg}$. of ethinyloestradiol (" anovlar").

\section{Large-scale Clinical Trial}

The efficiency of the tablet to be used had already been proved in the 536 women mentioned above. The objects of the present trial were to confirm this, to compare the incidence of side-effects with other available oral contraceptives, and to test the acceptability of this tablet to women in Britain. The organization of largescale trials under the auspices of C.I.F.C. has already been described in detail (Eckstein et al., 1961 ; Mears, 1961).

\author{
ELLEN C. G. GRANT, M.B., Ch.B. \\ D.Obst.R.C.O.G. \\ Medical Officer, Headquarter Oral Contraceptive Trial, \\ Council for the Investigation of Fertility Control
}

The volunteers had to satisfy the following criteria: to be under 40 years at the time of beginning the trial, to have proved their fertility, to have at least one living child of the present marriage, to have had not more abortions than children, to have a body weight not exceeding 11 stone $(70 \mathrm{~kg}$.), to reside within easy reach of the clinic, to be prepared to come regularly for examination, and to remain in the trial for a minimum of six months (and to use no other form of contraceptive). In every case the patient and her husband signed a consent form and the general practitioner was informed of the patient's participation in the trial and of the tablet to be used. The patient's first visit was arranged wherever possible for the premenstrual period so that the examination could include a routine endometrial biopsy. At the first visit a full gynaecological and obstetric history was obtained. She was given a general examination which included breast examination, blood-pressure, haemoglobin, weight, pelvic examination, routine cancer smear, and where possible endometrial biopsy.

Every patient was given two bottles, each containing 20 tablets, and was told to start, after the next monthly period, taking one tablet every night from the fifth day of each menstrual cycle for 20 days (counting the first day of bleeding as day 1). They were told that if slight staining or spotting of blood occurred while taking the tablets they were to continue to take them (marking "spotting" on the record card), but if as much bleeding as in a normal period occurred before the 20 tablets had been finished they were to stop taking them and resume the next course of 20 in the usual way on the fifth day. They were warned that amenorrhoea occasionally might occur, and if so they should allow five clear days and start the next course of tablets. They were instructed to take the tablets regularly, but that if they forgot the tablet at night they should take it the next morning. All patients were given a record card on which to note days of the menstrual period, of tablet-taking, and any side-effects which occurred, as well as to record when intercourse took place. They were instructed to return to the clinic at the beginning of the second cycle and three-monthly thereafter. An examination of each patient was made after three cycles 
of treatment to note effect on breast, pelvic organs, weight, etc. (Cancer smears are repeated six-monthly and endometrial biopsies from time to time as may be convenient.) A preliminary analysis has now been made of the first 11 months of this trial.

\section{Characteristics of Women Who Join the Trial}

It is interesting to note the type of women who volunteer for trial of this new contraceptive method. The 135 women who joined the trial have 288 live offspring, an average of 2 plus per couple; $22 \%$ were under 25 years of age, $63 \%$ were aged 25 to 34 , and $15 \%$ were 35 and over. The majority of the volunteers were under 35 and were therefore still well within the child-bearing years. Of the 288 conceptions, 248 were claimed to have taken place within the first two months of trying. This of course includes the failures of previous contraceptive measures and those who conceived immediately. This means that only 40 of the pregnancies in this group of women took longer to produce than two months. Tietze has suggested that conception takes place in the first two months in only one out of three couples, so that this was obviously a highly fertile group.

Practically all the woman expressed a dislike of previous contraceptive methods: 90 of them had at some time used the diaphragm and chemical method and 67 the sheath method of birth control. Between them they claimed 132 failures with previous contraceptive methods, though on close questioning only 49 of these seemed to be failures of the method, the other 83 being failures due to the patient making irregular and non-conscientious use of the particular method; also, many of them complained that they did not feel safe with contraceptive methods because of previous failures.

Conscientiousness.-Table I shows that 4 of the 170 patients enrolled failed to return when requested; it is not known whether these patients gave up after starting or before starting the method. The other 166 patients have completed at least one cycle, and indeed

TABLE I

\begin{tabular}{c|c|c|c}
\hline $\begin{array}{c}\text { No. of Patients } \\
\text { Enrolled }\end{array}$ & $\begin{array}{c}\text { No. Completed } \\
\text { 1st Cycle }\end{array}$ & $\begin{array}{c}\text { No. Failed } \\
\text { to Return }\end{array}$ & $\begin{array}{c}\text { No. Completed } \\
\text { Cycles }\end{array}$ \\
\hline 170 & 166 & 4 & 1,023 \\
\hline
\end{tabular}

have continued so far in the trial for 1,023 cycles. Of these 166, 24 have missed 31 tablets and failed to take another in the morning as suggested. Six patients forgot to take a tablet at night and took it the next morning, 12 times - that is, an average of twice per patient, though none of these patients has missed more than one tablet in any one cycle. It is interesting, however, that 30 patients out of 166 should make a mistake over tablettaking when they were all seemingly so anxious not to become pregnant.

\section{Efficiency of Method}

No pregnancies have occurred so far in this trial, whether among the women who have taken them conscientiously or those who have missed an occasional tablet. In such a highly fertile group of women there can be no doubt of the extraordinary efficiency of this method. Previous trials with other oral progestogens have shown an occasional pregnancy due to failure of the method and several pregnancies due to failure of the patients. So far there have been no patient-failures with this product. Although trials of anovlar have not gone on for so long as trials of some other oral progesterones as ovulation inhibitors, it should be remembered that the occasional tablet-failure has been in the first cycle of medication. Fewer patients have been upset by preliminary side-effects with this than with other oral contraceptives, and this fact may have a bearing on the $100 \%$ efficiency encountered so far.

\section{Side-effects}

Experience of patients taking previous oral contraceptives, a considerable proportion of whom developed side-effects (particularly nausea) which were disturbing and occasionally alarming, led us to warn them that some women have side-effects such as nausea, breast tenderness, and headache. Patients were reassured that if such side-effects occurred they would last for only a few days at the beginning of the first two or three cycles and would most likely disappear spontaneously. They were told to telephone if any doubts or difficulties arose. Without this prior warning and reassurance in previous trials undoubtedly some patients would have withdrawn in the first few days of tablet-taking. This same procedure was followed with patients taking part in the present trial.

Nausea.-The incidence of nausea-from $22 \%$ in the first cycle, reducing to $7 \%$ from the seventh cycle (Table II), with a small amount of vomiting-is rather

TABLE II.-Incidence of Nausea

\begin{tabular}{r|c|c|c|c|c}
\hline Cycles Completed: & 1 & 2 & 3 & $4,5,6$ & More than 6 \\
\hline No. woman-months .. & 166 & 159 & 150 & 356 & 192 \\
Nausea, slight & $22 \%$ & $7 \%$ & $12 \%$ & $6 \%$ & $7 \%$ \\
with vomiting & $3 \%$ & $1 \%$ & $1 \%$ & $1 \%$ & Nil \\
\hline
\end{tabular}

less than the incidence with other oral progestogens. The nausea, however, was very slight, was felt mainly in the morning, was readily relieved by antacids or antihistamines, and occurred for only a very few days at the beginning of the early cycles. Only one patient out of 166 telephoned in the first cycle because of severe nausea. This is much less than has been found with patients on previous oral contraceptives. We feel that warning patients of the possibility of nausea when using anovlar has probably inflated these figures and that they are not a true indication of the real incidence.

Abdominal Cramp and Dysmenorrhoea.-In no case did dysmenorrhoea get worse, and in $36 \%$ of cases it was much improved or disappeared completely. There was no change in $6 \%$, and $18.5 \%$ who reported an increase noticed irregular uterine spasms rather than true dysmenorrhoea, and these occurred mainly in the first cycle, then decreasing until they disappeared after three or four cycles. This finding is similar to the findings of Tyler et al. (1961) with $10 \mathrm{mg}$. of norethisterone. They found $35 \%$ improved and $7 \%$ no change.

Premenstrual Tension.-At their first visit patients were asked specifically for any history of headaches, irritability, depression, distension, tiredness, ankleswelling, and breast discomfort. After treatment there was no change in $5 \%$, there was an increase of symptoms in $11 \%$, and $26 \%$ noticed either an improvement or complete relief of signs of tension (Table III). It is possible that some who suffered from irritability and depression were relieved by freedom from the fear of pregnancy and were improved by the fact that their 


\begin{tabular}{|c|c|c|c|}
\hline & $\begin{array}{c}\text { No } \\
\text { Change }\end{array}$ & $\begin{array}{l}\text { Reported } \\
\text { Increase }\end{array}$ & $\begin{array}{l}\text { Reported } \\
\text { Decrease }\end{array}$ \\
\hline $\begin{array}{ll}\text { Premenstrual tension } & \ldots \\
\text { Headache ... } & . \\
\text { Breast discomfort } & \ldots \\
\text { Abdominal distension } & \ldots\end{array}$ & $\begin{array}{l}5 \% \\
7 \% \\
5 \% \\
2 \%\end{array}$ & $\begin{array}{l}11 \% \\
18 \% \\
13 \% \\
2 \%\end{array}$ & $\begin{array}{l}26 \% \\
8 \% \\
15 \cdot 5 \% \\
9 \%\end{array}$ \\
\hline
\end{tabular}

bleedings occurred so regularly-often at the same hour after the last pill each cycle ; but premenstrual symptoms in many patients were undoubtedly improved. A more persistent complaint was headache occurring in the interval between tablets and during the periods, whereas headache previously tended to be premenstrual. The incidence of all complaints tended to diminish with each cycle, although the numbers involved are too small to prove this conclusively.

Libido.-Records have been kept at each visit of the number of times of intercourse in each cycle and of whether the patient found any difference in her libido (used here in the sense of sex desire). The majority of patients claimed to enjoy intercourse much more, as they were free from fear of pregnancy and from the messy preparations involved by other methods. This is hardly surprising, since so many of them came because of their dislike of other methods; and this probably accounts for the high incidence reported. Tyler et al. (1961), for example, reported $15 \%$ increase in libido with $10 \mathrm{mg}$. of norethisterone. We are not convinced that there are any cases of real increased libido in this series, though six patients claimed to have some increase and five thought they had less interest since taking oral contraceptives. A few of these may be genuine, but some have had no satisfaction using other methods; undoubtedly some patients come hoping the pill will be a panacea for their sexual difficulties, so that they may be expressing their disappointment at its failure to do so rather than a real decrease in libido.

Change in Weight.-A gain in weight of more than $3 \mathrm{lb}$. (1.4 kg.) has been the most frequent side-effect, occurring in $45 \%$ of cases (Table IV), and indeed $13 \%$

TABLE IV.-Change in Weight

\begin{tabular}{c|c|c|c}
\hline \multirow{2}{*}{ No Change } & \multicolumn{2}{|c|}{ Increase } & \begin{tabular}{c} 
Decrease \\
\cline { 2 - 3 }
\end{tabular} \\
\cline { 2 - 3 } & $3 \mathrm{lb} .(1 \cdot 4 \mathrm{~kg})+$. & $7 \mathrm{lb} .(3 \cdot 2 \mathrm{~kg})+$. & $\mathrm{kg})$. \\
\hline $46 \%$ & $13 \%$ & $9 \%$ \\
\hline
\end{tabular}

have gained $7 \mathrm{lb}$. (3.2 kg.) or more ; $9 \%$ have had a decrease of more than $3 \mathrm{lb}$. This has occurred more readily in patients who have always had weight problems and has taken place soon after the start of treatment. The average gain in weight has been unrelated to the length of treatment, being 6-7 lb. $(2.7-3.2 \mathrm{~kg}$.) whether after one, three, or six cycles. One patient withdrew because she had gained 1 stone $(6.4 \mathrm{~kg}$.) in weight, but she lost $7 \mathrm{lb}$. (3.2 kg.) of this the following month. The increase in weight in many patients has been in the waist and breasts (the majority have mentioned specifically an increased appetite ; a few who have been particularly thin have been very pleased to have increased in weight), so that the gain would appear to be an anabolic effect; but this requires further investigation. This incidence of weight increase is very similar to that recorded by other workers: Greenblatt (1958) found that most patients taking 20-30 mg. of norethisterone gained weight; Tyler et al. (1961) found $21 \%$ of patients taking norethisterone gained $7 \mathrm{lb}$. $(3.2 \mathrm{~kg}$.) and over. Obviously this is something which must be watched.

\section{Acceptability}

This method has so far proved very acceptable to the patients. Almost all have expressed approval of it and their delight at being able to use a contraceptive method which was unrelated to individual coital acts. They have felt confident and happy, with a sense of well-being, and so have been enabled to enjoy intercourse more. Moreover, as shown above, many patients have lost previous symptoms such as dysmenorrhoea, premenstrual tension, etc., while even those who developed symptoms alleged to be due to the pill have liked the method so much that they have not been put off by them.

The number of patients who have withdrawn from the trial is very small (Table V). It is unlikely that the four

\begin{tabular}{c|c|c|c|c}
\multicolumn{2}{c}{ TABLE V.-Number of Patients Withdrawing from Trial } \\
\hline $\begin{array}{c}\text { No. } \\
\begin{array}{c}\text { Completed } \\
\text { at Least } \\
1 \text { Cycle }\end{array}\end{array}$ & $\begin{array}{c}\text { No. } \\
\text { Completed } \\
\text { Cycles }\end{array}$ & $\begin{array}{c}\text { Non- } \\
\text { starters }\end{array}$ & $\begin{array}{c}\text { Withdrawing } \\
\text { Because of } \\
\text { Side-effects }\end{array}$ & $\begin{array}{c}\text { No. } \\
\text { Withdrawing } \\
\text { for Other } \\
\text { Reasons }\end{array}$ \\
\hline 166 & 1,023 & 4 & 7 & 10 \\
\hline
\end{tabular}

non-starters had in fact used the pill or we would have heard from them. One patient withdrew temporarily because her husband went away from home: seven patients withdrew because of side-effects of the pill, three because of headaches. The first of these developed severe headaches, which previously had been cured by an osteopath but which had recurred since taking the pills; these headaches were almost certainly psychogenic. Another patient withdrew because of tiredness, a decrease of libido, and a gain in weight of 1 stone (6.4 kg.), another at her husband's request as her libido seemed to decrease and this caused him anxiety, but it also seemed that he preferred to take the initiative and control of contraception. The sixth patient withdrew because of two heavy breakthrough bleedings-she had a severely eroded cervix - and the last one because of anxiety over epimenorrhoea.

\section{Cycle Control}

As in previous trials (Eckstein et al., 1961 ; Mears, 1961), breakthrough bleeding is defined as bleeding of an amount equal to that of a normal period occurring during the taking of tablets so that the patients stop medication. The extent of breakthrough bleeding with this tablet has been remarkably small. The highest incidence found in any one month so far has been $8 \%$, and the overall average is $5.1 \%$ of all cycles (Table VI).

TABLE VI

\begin{tabular}{c|c|c|c}
\hline \multirow{2}{*}{$\begin{array}{c}\text { No. Woman } \\
\text { Months }\end{array}$} & $\begin{array}{c}\mid c \\
\text { Creakthrough } \\
\text { Bleeding }\end{array}$ & Spotting & Amenorrhoea \\
\cline { 2 - 4 } & $5 \cdot 1 \%$ & $9 \%$ & $2 \cdot 5 \%$ \\
\hline 1,023 & & $9 \%$ & \\
\hline
\end{tabular}

Similar results have been found by other investigators -for example, Peeters, van Roy, and Oeyen (1960) reported breakthrough bleeding in $4 \%$ of cycles, Swyer (1962) in $1.3 \%$ of 150 cycles. Thus the amount of breakthrough bleeding is much less than that reported 
in the trials of any other oral contraceptive. Our clinical impression, too, is that this product gives cycles of almost clockwork precision. The gap between the end of tablet-taking and the beginning of bleeding was remarkably constant, in most cases being two to three days. Table VII shows the average length of the cycles experienced by the patients in this trial.

TABLE VII.-Average Length of Cycles

\begin{tabular}{|c|c|c|c|c|c|}
\hline $\begin{array}{l}\text { Length of cycle (days) } \\
\text { Incidence }\end{array}$ & $\begin{array}{r}8-24 \\
5 \%\end{array}$ & $\begin{array}{l}25 \\
2 \%\end{array}$ & $\begin{array}{c}26 \\
75 \%\end{array}$ & $\begin{array}{r}27 \\
19 \%\end{array}$ & $\underset{2.5 \%}{\text { Amenorrhoea }}$ \\
\hline
\end{tabular}

Spotting, too, would appear to be less with anovlar, being $18 \%$ in the first cycle, with an overall incidence in all cycles of $9 \%$. Even in the 31 cycles where a tablet was missed there were only five cycles of breakthrough bleeding and one cycle of spotting. This suggests an interesting difference between this product and norethynodrel, as patients on norethynodrel who omit one tablet are very liable to have spotting and/or breakthrough bleeding.

The amount of bleeding or menstrual flow is altered in a considerable proportion of patients on this product. This figure has been analysed for the first and third cycles as being typical of the picture presented. An increase in the amount of bleeding was found in $5 \%$ and $3 \%$ of cases whereas $70 \%$ and $50 \%$ of patients noticed a reduced amount of flow. This is quite marked in many of these cases. It is quite usual for a woman who normally has a menstrual flow of six to seven days to find it reduced to three or four days. In fact the amount of menstrual flow is often so reduced that only a scanty brown discharge occurs, and this can be a source of anxiety to some women.

The incidence of amenorrhoea is similar to that found in most trials of other oral contraceptives. Tyler et al., using $10 \mathrm{mg}$. of norethisterone, reported amenorrhoea in $6 \%$ of cycles; Pincus et al. (1959), in trials in Humacao, Puerto Rico, and Haiti, reported $2.2 \%$; while the incidence in trials of norethynodrel in this country (Eckstein et al. 1961; Mears, 1961) has varied from 1 to $9 \%$. The lowest incidence of amenorrhoea with norethynodrel was with the tablet with the highest oestrogen content - that is, $2.5 \mathrm{mg}$. plus $0.15 \mathrm{mg}$. of ethinyloestradiol-3-methyl ether. When norethynodrel is used it seems that in amenorrhoeic cycles patients often have some spotting during tablet-taking and none during the gap, whereas the patients on norethisterone acetate have the spotting during the gap without periods, which is therefore regarded as a menstrual flow.

Masculinization.-Four patients taking part in the trial have complained of acne vulgaris which was not present beforehand, though other patients have reported that their skin has been clearer than before medication. Acne has also been reported in trials of other oral contraceptives. There has been no evidence of any virilization of the patients taking part in this trial. Much prominence has been given to this possibility since cases have been reported in the medical literature of foetal masculinization after the administration of certain progestogens during pregnancy. These cases have in fact occurred where large doses have been given during the first 13 weeks of gestation to preserve pregnancy, and no cases have been reported with the much smaller doses used for oral contraception. No pregnancies have occurred in any patients taking anovlar as an oral contraceptive in this country, but, even should pregnancy occur, with proper medical supervision patients should not go on taking the tablets. Care is taken to ensure that no patient is pregnant when she begins taking the tablets.

Post-coital Tests.-Post-coital examination of cervical mucus has been carried out in 21 of these patients. In 15 the mucus was tenacious, tacky, and viscous, and, though quite clear, no active sperms were found. In five cases there were a few sluggishly moving sperms, and in one case there were still a considerable number of highly motile spermatozoa. These tests were all made between 9 and 14 hours after intercourse had taken place ; thus a normal ovulatory mucus was found in only one out of 21 cases, so that in the majority a considerable ieparture from normal was found.

Endometrial Biopsies and Vaginal Cytology.- Endometrium for a biopsy has been collected from 60 patients in the premenstrual phase before treatment, at various points in the cycle, and in various cycles during medication. Cytological smears and cancer smears have been taken routinely from every patient before treatment and six-monthly thereafter. The cancer smears have all been negative except for one which showed early precancerous change. The cytological findings and the biopsies will be compared in a later paper.

\section{Summary}

An account is given of a large-scale trial carried out under the auspices of the Council for the Investigation of Fertility Control to confirm the efficiency and to test acceptability of a further oral contraceptive, anovlar (4 mg. of norethisterone acetate plus $0.05 \mathrm{mg}$. of ethinyloestradiol), which had already been used for 2,292 cycles in 536 women in trials elsewhere.

The women who were accepted from the many who volunteered were a highly fertile group who practically all disliked conventional contraceptive methods.

So far 166 women have taken part for 1,023 months : only seven have withdrawn from the trial because of side-effects, so that this would appear to be a most acceptable form of contraception. The product was well tolerated and side-effects were few. The most frequent side-effect was an increase in weight. Although $22 \%$ of patients had some degree of nausea in the first cycle, this was very slight and was not disturbing to them and was much less than with other oral progestogens used by us so far.

Cycle control was remarkably good, the incidence of breakthrough bleeding being $5.1 \%$, spotting $9 \%$, and amenorrhoea $2.5 \%$ of all cycles. There was a decrease in the amount of menstrual flow in rather more than $60 \%$ of patients and $26 \%$ found an improvement in premenstrual tension.

No symptoms of virilization are reported.

As a result of this and other trials reported in the literature, the Council for the Investigation of Fertility Control has recommended anovlar for use as an alternative oral contraceptive in F.P.A. clinics.

The members of the Clinical Trials Committee of the Council for the Investigation of Fertility Control are: Dr. G. I. M. Swyer (chairman), Dr. P. M. F. Bishop, Dr. Margaret Jackson, Professor R. J. Kellar, Dr. J. A. H. Waterhouse, Professor A. S. Parkes, and Dr. Eleanor Mears (medical secretary). 


\section{REFERENCES}

Eckstein, P., Waterhouse, J. A. H., Bond, Glenys M., Mills, W. G., Sandilands, Dorothy M., and Shotton, D. Margaret (1961). Brit. med. J., 2, 1172.

Grant, A. (1961). Med. J. Aust., 2, 936.

Greenblatt, R. B. (1958). Amer. J. Obstet. Gynec., 176, 626.

Jackson, Margaret H. (1961). Proc. roy. Soc. Med., 54, 983.

Margulis, R. R., Ladd, J. E., Fahey, M. F., and Walser, H. C. (1961). "Inhibition of Ovulation by Norethisterone Acetate," 3rd International Congress for Gynaecology and Obstetrics, Vienna.
Matsumoto, $S$, Ito, $T$, Inoue, $S$, Kuribara, $M$., and Sato, $T$. (1961). Z Zbl. Gynäk., 83, 1485 .'

Mears, Eleanor (1961). Brit. med. J., 2, 1179.

Peeters, F., van Roy, M., and Oeyen, H. (1960). Geburtsh. u. Frauenheilk., 20, 1306.

- (1961). Med. Klin., 56, 1679.

Pincus, G., Rock, J., and Garcia, C. R. (1960). Proceedings of International Conference on Planned Parenthood, New Delhi, 1959, p. 216. International Planned Parenthood Association, London.

Swyer, G. I. M. (1962). C.R. Soc. franç. Gynéc. In press.

Tyler, E. T., Olson, H. J., Wolf, L., Finkelstein, S., Thayer, J., Kaplan, N., Lewin, M., and Weintraub, J. (1961). Obstet. and Gynec., 18, 363.

\section{PASSIVE IMMUNization AgaINST TETANUS WITH HUMAN IMMUNE GLOBULIN}

BY

\author{
SYDNEY D. RUBBO, M.D., Ph.D., Dip.Bact. \\ Professor of Bacteriology, Department of \\ Bacteriology, University of Melbourne
}

The clinician who is called upon to treat an injured person is always confronted with the problem of specific prophylaxis against tetanus, a disease of extreme rarity but one of extreme severity should it occur. It is the latter consideration which usually dictates the management of a case, and, as a result, passive immunization with equine tetanus antitoxin is used far more often than would appear necessary or desirable. If this form of prophylaxis carried no complications then there would be little point in questioning its widespread use, but the sequelae of antiserum therapy are frequent and often disabling. Indeed, a special committee of the London Academy of Medicine, Ontario, recommended mass immunization with tetanus toxoid not to reduce the incidence of tetanus, which was negligible, but to lower the morbidity and mortality of tetanus antitoxin allergy, which was considerable (Toogood, 1960). From a review of recent papers we believe that $5-6 \%$ of persons receiving horse serum will exhibit post-injectional complications of varying severity. It is therefore understandable that there is a great reluctance to administer heterologous serum in tetanus prophylaxis.

The idea of using homologous human antitoxin has been suggested by some workers (Turner, Stafford, and Goldman, 1954; Smolens, Stokes, and Vogt, 1957 ; Stafford, 1960) but in the absence of any information on the dosage and the duration of passive immunity homologous serum has never been seriously considered. In an earlier study (Suri and Rubbo, 1961) it was shown by animal experiment that homologous serum was at least one hundred times more effective than the heterologous type. Further, it was found that a dose of 200 units of homologous antitoxin produced serum levels of $0.02 \mathrm{unit} / \mathrm{ml}$. in five out of seven persons for at least 21 days. This concentration of antitoxin, if maintained throughout the incubation period, has been estimated by Bruce (1920) to be protective.

In view of these encouraging results we have extended the above observations in order to define more precisely what antitoxin levels might be expected in humans who have been passively immunized with different doses of a purified preparation of human immune globulin. The findings, which are presented here, provide a strong case for considering the use of this preparation in relatively low doses in passive immunization against tetanus.

\author{
J. C. SURI, M.B., B.S., M.Sc. \\ Assistant Director, Central Research Institute, \\ Kasauli, Punjab
}

\section{Materials and Methods}

Twenty-seven healthy non-immune adults of European origin and six of Indian origin were passively immunized by intramuscular injection of human tetanus antitoxin. The antitoxin, which was kindly supplied to us by Dr. W. E. Ward, of Cutter Laboratories, U.S.A., was prepared from the sera of actively immunized Europeans by the Cohn ethanol fractionation procedure. It consisted of $165 \pm 15 \mathrm{mg}$. $/ \mathrm{ml}$. of $100 \%$ pure gammaglobulin, $90 \%$ of which was tetanus-immune globulin. This antitoxin, hereinafter referred to as human immune globulin, carried no risk of transmitting viral hepatitis.

All volunteers were bled (approximately $15 \mathrm{ml}$. of blood was taken) before immunization and at weekly intervals for three weeks. The antitoxin content of the sera was determined by mouse-protection tests using three mice for each serum dilution as previously described (Suri and Rubbo, 1961).

\section{Results}

In Table I the antitoxin levels for the 33 subjects are listed. The figures show remarkably little variation between different individuals receiving the same dose of antitoxin and the rate of disappearance in each dose group follows a straight-line curve. The constancy of antitoxin level and its slow die-away rate contrasts strongly with the variability found in passive immunization with heterologous serum. The only discrepancy, which was consistently observed, was the lower levels exhibited by the Indian subjects when compared with Europeans receiving the same dose of antitoxin-namely, 10 units $/ \mathrm{kg}$. of body weight. This curious difference is discussed later.

When the averages of the titrations are graphed (Fig. 1) the curves fall neatly into place in respect to dosage, and the disappearance rate is slow but constant. The Indian subjects (Fig. 2) appear to eliminate the antitoxin more rapidly, and this is consistent with the lower antitoxin levels found at the first and subsequent bleedings. In general, however, these results closely confirm our previous titrations and provide a basis for discussion of the value of human immune globulin in tetanus prophylaxis. 